\title{
Discapacidad y medios de comunicación; entre la información y el estereotipo
}

\author{
Francisco Perujo Serrano \\ Licenciado en Periodismo por la Universidad de Sevilla, \\ Director de la revista Entre Todos \\ Responsable del gabinete de prensa de la Federación Andaluza de Minusválidos \\ Asociados (FAMA)
}

\section{RESUMEN}

La discapacidad ha dado en España un paso significativo hacia delante durante la última década. El compromiso de las instituciones, la existencia de una legislación específica y la progresiva vertebración del colectivo a través de un incipiente movimiento social ha posibilitado la conducción de sus demandas hasta los círculos donde se producen las tomas de decisiones y su aparición entre las noticias de actualidad de los distintos medios de comunicación. La superación de un formato periodístico caduco para la discapacidad, basado en el estereotipo y fáciles generalizaciones, es el gran reto del colectivo en estos momentos en su relación con los medios.

\begin{abstract}
The disability has given forward in Spain a significant sep during the last decade. The commitment of the public institutions, the existence of a specific legislation and the progressive organization of the disabled community through an incipient social movement have facilitated the conduction of their demands until the circles where the taking of decisions and their appearance take place among the news of present time of the different mass media. The overcome of a journalistic format expires for the disability, based on the stereotype and easy generalizations it is the great challenge of the community in these moment in its relationship whit the mass media.
\end{abstract}

Palabras claves: Discapacidad/Medio de comunicación/Información/Estereotipo.

Key Words: Disability/Media/Information/Stereotype.

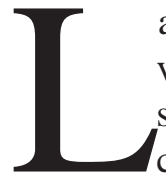

a discapacidad es un componente de la actualidad periodística. Su relevancia es cada vez mayor, no hay duda. En los últimos años se han sentado los cimientos para una relación recíproca entre los medios y el colectivo donde la lucha por aparecer dentro del territorio de la noticia se ha caracterizado por la utilización de unos modos, la predilección por unas fórmulas estandarizadas de tratamiento y la acomodación del trabajo de las entidades al funcionamiento de los profesionales de la comunicación con la creación de gabinetes y oficinas de prensa especializados. 
Entendemos por actualidad periodística, "la selección de aquellos acontecimientos que, en razón de su interés humano y actual, ganan la atención en un

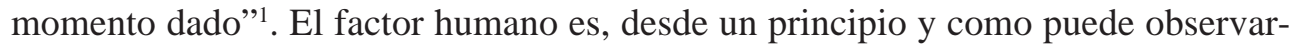
se, el motivo principal que encuentran los periodistas en el universo de la discapacidad para convertirlo con frecuencia en noticia.

Por eso, el competido panorama de informaciones que pugnan entre sí por un hueco mínimo dentro de la actualidad encuentra en la discapacidad un protagonista emergente. En esa serie de cuestiones de mayor calado mediático o, tal y como afirma Ángel Benito, en ese conjunto de "noticias que interesan y afectan a los públicos en un momento dado", aparece con entidad propia pero con la necesidad de reformularse ante la opinión pública el colectivo de la discapacidad.

La plena normalización socio-laboral de las personas con discapacidad debe superar en nuestro país dos graves inconvenientes, hoy verdaderos problemas estructurales: el desempleo, más del $75 \%$ de los discapacitados españoles se encuentra en paro, y el escaso nivel formativo, apenas un $6 \%$ del colectivo consigue en la comunidad andaluza, por ejemplo, llegar a la universidad. El fallo se encuentra en los escalones previos dentro del proceso de enseñanza reglada y se irradia hasta los estudios superiores, sólo un ínfimo $1 \%$ finaliza con éxito sus estudios universitarios.

Este curso sinuoso de avances con serias limitaciones ha marcado la evolución del movimiento asociativo vinculado al universo de la discapacidad y el tratamiento que el colectivo ha recibido desde los medios de comunicación.

Los progresos, aún evidentes, avanzan a media velocidad lastrados por la persistencia de importantes obstáculos que ralentizan la incorporación normalizada de las personas con discapacidad a todos los órdenes de la vida. La información sobre el colectivo, si bien ha crecido en términos cuantitativos, debe someterse también a un proceso de revisión conceptual para evitar perversiones inadecuadas que son consecuencia, en la mayoría de las ocasiones, de la utilización sistemática de estereotipos como instrumentos de aproximación a su realidad empírica, siempre superficiales e inexactos.

En este sentido, el peso y la influencia de los medios de comunicación juegan un papel determinante en la transmisión del hecho informativo que, en palabras de García Núñez, "no consiste sino en la recopilación de una serie de datos y hechos de actualidad (las fuentes), por parte de unos agentes (los periodistas), que mediante un ulterior tratamiento de dichos datos (la redacción y la

1 BENITO, Ángel: La invención de la actualidad-Técnicas, usos y abusos de la información-, Fondo Cultura Económica, Madrid, 1995, p. 12.

2 IDEM: p. 9. 
documentación), los ponen en conocimiento de la comunidad (los lectores), a través de un medio de comunicación (el periódico)"’3.

Es necesario, por lo tanto, conseguir también la integración en el terreno mediático, donde aún subyace unas fórmulas de tratamiento sobre la información de la discapacidad poco rigurosas, unos enfoques basados en generalizaciones, una apelación constante al estereotipo como herramienta para captar la realidad del colectivo a partir de simplificaciones aceptadas por la mayoría y una perspectiva del universo de la discapacidad que, en modo alguno, facilita la integración del discapacitado en su entorno.

Resulta, de esta manera, indispensable instalar la discapacidad de forma definitiva en el plano del proceso periodístico, en los esquemas habituales de generación y difusión de informaciones de actualidad con objeto de ensanchar la ocupación de un ángulo social aún hoy reducido y penetrar con un mensaje diferenciado entre los lectores desde los medios de comunicación, porque, y así lo reconoce el propio García Núñez, "uno de los caracteres esenciales del periódico como tal es su naturaleza pública, su venta libre y en consecuencia el libre acceso de todo el mundo a sus contenidos publicados"4.

La discapacidad debe romper con su tradicional aislamiento en la sociedad, en gran medida motivado por sus notables carencias a la hora de reclamar un mayor espacio en el ámbito de lo noticiable. Sólo así, el colectivo podrá traspasar sus propios límites, ser más y mejor conocido, colarse entre las cuestiones preferentes que conforman la actualidad y combatir unas fórmulas de acercamiento periodístico cuyo saldo le ha sido siempre más bien desfavorable. En esencia , "los medios, con sus noticias, empujan al hombre a ponerse en contacto con el mundo. Las noticias son trozos de la vida real", que nos serían ajenos sin la capacidad difusora de los primeros.

La aparición durante los últimos años de revistas (Vado Permanente, Minusval, En Marcha, Entre Todos, etc.) y programas especializados (Solidarios) en el ámbito de la discapacidad, la puesta en marcha de iniciativas públicas para la integración del colectivo sostenidas en importantes dotaciones presupuestarias como los programas europeos Horizon e Integra-, la investigación y el estudio emprendido desde escuelas y facultades universitarias sobre diferentes aspectos vinculados al mundo de la discapacidad (Ciencias de la Educación, Psicología, Trabajo Social, Ingeniería, Arquitectura o Ciencias de la Información), el terreno que ganado en los informativos de actualidad por las noticias de carácter social y, especialmente, la creación de gabinetes de prensa y comunicación en el seno de las asociaciones de discapacitados más consolidadas e influyentes, han sentado las

3 GARCIA NUÑEZ, Fernando: Cómo escribir para la prensa, Europea de Ediciones, Madrid, 1985, p. 16.

4 IDEM, p. 21. 
bases para modificar el orden de cosas vigente y provocar el comienzo de la otra normalización del colectivo; la que afecta a los medios de comunicación.

En una sociedad como la nuestra, la integración de sectores de población con identidades, características y problemáticas propias es una garantía entrecortada si no es asumida, entendida y aplicada desde los instrumentos más determinantes en la transmisión de mensajes, de pautas de conducta, de comportamientos y de cultura; los medios.

Estos mecanismos de difusión masiva se han convertido en "una institución social. Los comunicadores son parte de esa institución. Los medios tienen que satisfacer las necesidades culturales, políticas y económicas de la sociedad"5, de ahí su definición como medios de comunicación sociales.

$\mathrm{Su}$ compromiso en este terreno es incuestionable. La sociedad de la comunicación y de las nuevas tecnologías de la información exige una normalización paralela en el espacio de los propios medios, sin la cual resultan insuficientes todos los esfuerzos realizados desde instituciones, entidades privadas y movimientos asociativos.

Liderados por los entes de titularidad pública, los medios de comunicación de sociedades avanzadas tienen aún hoy la asignatura pendiente de reservar un tratamiento informativo riguroso a la diversidad, a los colectivos minoritarios, a segmentos de población que se presentan ante la opinión pública con unos intereses y una exigencias comunes, pero que apenas son conocidos, y cuando lo son, se construye de ellos una percepción equívoca mediante superficialidades y fáciles estereotipos.

El mundo de la discapacidad necesita de la implicación activa de los medios para conocerse mejor y ser conocido por el resto de la sociedad. Esta simbiosis mejorará en un futuro próximo la relación del colectivo con su entorno, cambiará la percepción generada en la opinión pública y modificará la naturaleza de los mensajes que, mediante la interlocución de empresas informativas, terminan calando en la sociedad.

La discapacidad se ha convertido en una fuente de noticias para los medios, es decir, forma parte de la actualidad. Siempre lo ha sido, pero ahora se ha entrado en una sistemática permanente de intercambios donde la transferencia de informaciones es mucho más fluida y más frecuente. La arquitectura aún incipiente de un movimiento asociativo cada vez mejor organizado y la aparición de los primeros gabinetes de prensa propios ha establecido un circuito básico gracias al cual los medios encuentran portavoces y profesionales capacitados en la elaboración de mensajes adscritos a las fórmulas y a los principios de redacción del periodismo.

5 VARIOS: Medios de comunicación social. Fundación Germán Sánchez Ruipérez., Madrid, 1992, p. 67. 
Este orden de factores ha multiplicado exponencialmente el número de noticias sobre el sector de la discapacidad tanto en los rotativos como en los informativos de las emisoras de radio y televisión. El gran reto, en estos momentos, es pulir aún más la imagen que los medios de comunicación proyectan sobre el colectivo, erradicar los recursos del lenguaje que enfatizan la sensibilidad emocional por encima del rigor informativo, combatir el estereotipo y, en la medida de lo posible, que descanse la emisión de los mensajes en gabinetes de prensa profesionalizados.

"El estereotipo viene a referirse a cualquier cosa que se repita sistemáticamente de la misma forma, sin variación",, asegura José Ignacio Cano. Quien añade, además, que éste "no se elabora cada vez que uno se enfrenta a la situación sino que se recurre a una estructura ya preparada en anteriores ocasiones" ${ }^{\text {" }}$. La utilización repetitiva de este recurso fortalece la creación de categorías en torno al mundo de la discapacidad, basadas en la superficialidad y en la generalización.

La apuesta por un nuevo periodismo para la discapacidad supondría la erradicación de aquellas tendencias, tan utilizadas por otra parte, que inciden en el techo emocional del mensaje por encima de su capacidad informativa, porque, comparte esta opinión Ángel Grijelmo, "algunos periódicos de formato serio toman del sensacionalismo el escaso plazo de caducidad para lo que se ha dicho y la yuxtaposición de hechos que invita a deducir causalidad sin suficiente base"8. A falta de una prensa sensacionalista en España como ocurre en la mayoría de los países europeos, los medios de comunicación generalistas adoptan algunos de sus esquemas, porque, a pesar de apostar por un estilo ajeno a los postulados clásicos del amarillismo populista, no son entes impermeables, por lo que se encuentran afectados en ocasiones por algunos de los procedimientos, en cuanto al enfoque y al tratamiento, típicos de la prensa amarilla.

\section{El estereotipo como recurso informativo}

Nuestra realidad social es heterogénea, compleja y cambiante. A partir de finales del XIX se produce una notable transformación del mundo occidental que muchos sociólogos calificaron desde el principio como sociedad de masas. Procediendo a un estudio somero de las estructuras actuales de la sociedad humana y de sus ramificaciones en plena era tecnológica, el análisis, ya de entrada, "ha

6 CANO GESTOSO, José Ignacio: Los estereotipos sociales: el proceso de perpetuación a través de la memoria colectiva, Ed. Universidad Complutense, Madrid, 1993, p. 5.

7 IDEM: p. 9

8 GRIJELMO, Álex: El estilo del periodista, Ed. Taurus, Madrid, 1997, p. 532. 
mostrado la complejidad de las direcciones diversas del cambio social en las varias sociedades, sus contradicciones, entrecruzamientos y mutuas dependencias y subornaciones. Un mundo con esas propiedades se presta naturalmente a una multiplicidad de interpretaciones en lo que respecta a su futuro".

El fenómeno de concentración de grandes volúmenes de población en núcleos urbanos incentivó el proceso de industrialización, acrecentó el ritmo histórico y multiplicó la intensidad de los cambios tecnológicos, económicos, sociales y culturales.

La consolidación de un incesante flujo de innovaciones tecnológicas y científicas ha ocasionado tres consecuencias definitivas sobre la sociedad contemporánea: la aceleración de los acontecimientos, el recorte de las distancias gracias a la mejora de los transportes y al nacimiento de nuevos medios de comunicación y, por primera vez en la historia de la Humanidad, la posibilidad de ampliar los límites del mundo conocido en cada persona.

La aparición del periódico como primer medio de comunicación de masas convierte a los viejos rotativos en empresas informativas, regidas por el principio de la venta y el paradigma del negocio, y en referentes del conocimiento de la realidad. Esto es posible gracias a la universalización paulatina de la enseñanza primaria, la reducción de las tasas de analfabetismo y la eliminación de los costes tanto en la producción de noticias como en el acceso a la información cuando se consolidan la radio y televisión.

Desde entonces, el individuo no participa activamente en la emisión colectiva de informaciones. La difusión masiva de mensajes uniformes desde medios masivos, la concentración de la información en unos pocos actores privilegiados -"la información y la comunicación en el mundo y en España tienden a la concentración" ${ }^{10}$, añade Ramón Reig-, la creencia en la veracidad del proceso, la asunción de unos modelos de vida y el triunfo de unas escalas de valores adheridas a los regímenes parlamentarios donde las libertades de asociación, reunión, publicación y expresión se encuentran aseguradas y respaldadas desde la propia ley, permiten la solidificación de una nueva estructura social que condiciona el modo de percibir, la manera de entender y, finalmente, la forma de ponderar las cosas.

"Las nuevas generaciones conocen el mundo a través de los medios de comunicación más que de la escuela" 11 y forman gracias a ellos sus escalas de valores, sus esquemas de pensamiento y sus pautas para interpretar la realidad

9 GINER, Salvador: Sociología, Ed. Nexos, Barcelona, 1996, p. 272.

10 REIG, Ramón: Medios de comunicación y poder en España: prensa, radio, televisión y mundo editorial, Ed. Paidós, Barcelona, 1998, p. 36

11 LÓPEZ GARCÍA, Antonio: Escritura e información, Ed. Cátedra, Madrid, 1996, p.136. 
recibida. Un contexto que, por otro lado, es víctima de una nutrida población de actores sociales, de un vertiginoso ritmo de vida y de un continuado proceso de cambios continuos.

En este sentido, las ciencias sociales han evolucionado considerablemente y han mejorado sus métodos de investigación con la finalidad de comprender las claves del nuevo sistema, conocer la naturaleza del comportamiento humano, determinar los cambios preponderantes y, si es posible, preverlos para adelantarse en la toma de decisiones.

La aparición de nuevas formas de vida y de nuevos medios de comunicación ha posibilitado una relajación de las costumbres, cada vez menos influyentes, y una pérdida de valor de las relaciones interpersonales. Además de la familia y de la escuela, aparece un tercer elemento que va ganando terreno a las dos instituciones clásicas encargadas a lo largo de los siglos de educar a decenas de generaciones: los medios de comunicación de masas, auténticos intermediadores sociales en la producción, emisión y distribución de mensajes.

En consecuencia, los modelos de conducta junto a los esquemas de pensamiento penetran sin dificultad hasta el interior de los hogares a través de los medios de comunicación. La escuela mediática, la pedagogía de la pantalla o el aprendizaje por imágenes, como queramos definirlo, desestabiliza de manera total la balanza de nuestros conocimientos: más a través de los medios y muchos menos por nosotros mismos.

Aparecen nuevos valores para un nuevo espacio; el urbano. La ciudad provoca una mayor sensación de desarraigo. Los medios se convierten en instrumentos de enganche con la realidad. Ordenan y simplifican un mundo complejo y caótico, suministrando una información selectiva, precisa y clara. Por vez primera, el planeta está al alcance del individuo pero le es totalmente imposible conocer lo que pasa en él directamente.

La globalización de la economía ha propiciado una internacionalización paralela del sistema informativo. Los medios de comunicación de masas al amparo de grandes entramados empresariales y financieros han ampliado los límites de la galaxia Gutemberg y han modificado al alza las potencialidades de la aldea global de McLuham.

Nunca el hombre estuvo tan informado, ni tan aislado. Esta paradoja, junto con la enorme aceleración que ha adquirido nuestras vidas, nos conduce a la tesitura de que cada vez es mayor el conocimiento transmitido y adquirido que el experimentado. La realidad se convierte, así, en un todo aislado de nosotros que se nos entrega ya empaquetado a través de los medios de comunicación.

Estos mecanismos de captación y comprensión de la realidad reducen la aportación intelectual del individuo y transmiten el conocimiento de las cosas como un todo elaborado. Así, “el periódico actúa como un intérprete. Más aún, el 
periódico es un intérprete y el periodismo un método de interpretación de la realidad" 12 .

La actitud pasiva en nuestra condición de destinatarios nos coloca en una situación de incapacidad de respuesta en el seno de una sociedad de estructura romboidal, con una minoría política y económica dominante, una mayoría de clases medias y unos colectivos minoritarios excluidos y desfavorecidos, entre los que se han encontrado tradicionalmente las personas con discapacidad.

Aprendemos deprisa porque vivimos deprisa, y lo hacemos en la mayoría de los casos por derivación, porque no participamos en la producción de mensajes ni en la emisión de los mismos. Nos encontramos siempre en el extremo opuesto del proceso, situado al otro lado, como consumidores de noticias, opiniones y mensajes publicitarios que nos llegan prefabricados.

En consecuencia, "la primera tarea de los medios como intérpretes consiste en permitirnos descifrar y comprender por medio del lenguaje la realidad de las cosas que han sucedido" ${ }^{13}$, porque cualquier instrumento de comunicación colectiva es "el resultado de un proceso complejo, que comprende una serie de elecciones sobre lo que debe publicarse" 14 y que, posteriormente, recibimos como el único pedazo de actualidad que nos es accesible.

Por tanto, nuestro conocimiento de las cosas es indirecto, superficial, interesado, subjetivo, manipulado y condensado en unidades simples de significación a las que llamamos clichés, modelos o estereotipos. A través de ellos recibe la sociedad en buena medida la información sobre el colectivo de la discapacidad. No hay tiempo ni recursos para comprobarlos desde la individualidad de cada destinatario. Se aceptan por asimilación colectiva y apenas sufren modificaciones en la internalización que hace al recibirlos cada persona.

El estereotipo es, por naturaleza, una imagen preestablecida siempre cargada de valores previos sobre una determinada realidad que se queda sólo en una superficialidad probable. Es un constructo no contrastado, que neutraliza cualquier proceso inductivo personal y que nos vende una percepción acabada. "Supone también un alejamiento de la realidad... al no existir una alternativa acertada o exacta ... es pues un recurso cognitivo e inevitable sin el cual nos encontraríamos confusos en una realidad demasiado inestable y contradictoria, donde el estereotipo tiende a preservarnos del efecto desconcertante de intentar ver el mundo de modo constante" 15 .

12 GUTIÉRREZ PALACIO, Juan: Periodismo de Opinión, Ed. Paraninfo, Madrid, 1984, p. 13.

13 IDEM, p. 14.

14 GUTIÉRREZ PALACIO, Juan: Periodismo de Opinión, Ed. Paraninfo, Madrid, 1984, p. 13.

15 CANO GESTOSO, José Ignacio: Los estereotipos sociales: el proceso de perpetuación a través de la memoria colectiva, Ed. Universidad Complutense, Madrid, 1993, p. 23. 
Para el profesor Cano Gestoso, todos los estereotipos, entre ellos los que afectan al universo de la discapacidad, están compuestos de tres pilares básicos: el cognitivo, el social y el emocional, en la medida que se encuentran "altamente cargados con los sentimientos que están ligados a ellos" ${ }^{16}$, que se les atribuye por convención para elevar el nivel expresivo del discurso.

Se trata de un mal necesario, de una herramienta imprescindible para atrapar, comprender y retener el enorme flujo de información que emanan a diario desde los medios las sociedades complejas. "La información relacionada con el estereotipo se recuerda más. Más concretamente, el material estereotípicamente consistente es más recordado" ${ }^{17}$.

Todo lo extraño, lo minoritario, lo anormal, lo diferente, nos llega por medio de estereotipos, entre ellos, varios asociados a la discapacidad. Los medios de comunicación, en su papel de transmisores y difusores de mensajes colectivos, han fomentado con el tiempo la aparición y consolidación de estereotipos, cuyas atribuciones enganchan fácilmente con los condicionantes de la información periodística: directa, sencilla, breve y concisa.

El estereotipo se amolda sin problemas al formato periodístico de captación y elaboración de las informaciones. Establece categorías y empatías que facilitan la compresión de los mensajes. Reduce los tiempos y los modos de transmisión, favorece la percepción y constriñe la realidad a segmentos simples de fácil introyección.

Aunque muchos medios de comunicación han apostado por la especialización de sus contenidos y de sus profesionales, el redactor de plantilla abarca todo el arco de la actualidad. En los medios generalistas, la premura de tiempo y la falta de recursos convierte a los informadores en auténticos todo terrenos que, con un fluido control de las fuentes y un dominio de las técnicas de redacción periodísticas, son capaces de elaborar noticias de temáticas dispares.

En esta situación, la utilización de estereotipos compensa la falta de especialización temática, acrecentada, en buena medida, por la persistencia de una terminología diversa, poco precisa, vaga, que se presta a demasiadas interpretaciones. El uso en paralelo de una amplia tipología de conceptos para catalogar al colectivo de personas con discapacidad potencia la aparición de enfoques difusos que favorecen la estimulación de clichés en la opinión pública.

La primera constante en el tratamiento informativo de la discapacidad es la preferencia por la terminología más efectista. Con ella se abunda en las diferencias, se marcan las distancias y se muestran las debilidades del colectivo. Se

16 LIPPMAN, W: Public Opinion. Horcourt, New York, 1922, p. 96.

17 CANO GESTOSO, José Ignacio: Los estereotipos sociales: El proceso de perpetuación a través de la memoria selectiva, Ed. Universidad Complutense, Madrid, 1993, p. 558. 
buscan etiquetas que marquen una ruptura emocional en el destinatario, que le afecten a la hora de percibir la realidad y que alteren las pautas normales de percepción a través de agentes sensibilizadores.

La elección del concepto básico para identificar la discapacidad es el primer motor de distorsión en un largo proceso informativo marcado por una tendencia inevitable hacia el sensacionalismo. Cuando, recientemente, el Diario de Cádiz del 22 de junio pasado, el $A B C$ en su edición del 7 de julio de 2001 o El Correo de Andalucía en su ejemplar correspondiente al 12 del mismo mes titulan "Marginados limpiarán las calles en el verano", "La colaboración vecinal evita que tres personas impedidas mueran abrasadas en su vivienda" y "Un taxista salva a un inválido del fuego", respectivamente, están atornillando inconscientemente una nomenclatura de términos especialmente denostativa para el colectivo de la discapacidad.

El lenguaje es, tras la yuxtaposición de imágenes descontextualizadas, el segundo sustento esencial para la consolidación de cualquier estereotipo. El mundo de la discapacidad debe sufrir, primero, y combatir, después, este tipo de recursos que, desde la autoridad informativa de los propios titulares, marcan el tratamiento periodístico que se reserva a un colectivo donde los valores negativos (impedido, inválido, marginados,...) constituyen los elementos de fuerza más recurrentes para alcanzar la noticiabilidad.

No cabe duda que el titular "responde a la regla básica de comenzar por lo más importante" 18 y que en su interior se expresa "el contenido global de la noticia"19, por lo que incidir desde el encabezamiento de las informaciones en este abanico de caracteres marcadamente negativos supone toda una declaración de principios del periodista y la determinación por un enfoque que margina el más remoto resquicio de normalización social a través de la prensa.

De esta forma, se destacan los atributos menos amables del colectivo, aquellos que infieren con crudeza en los problemas y no en las soluciones. Se presenta la discapacidad como una realidad desprovista de virtudes, se apela a la emoción mediante la utilización de vocablos de gran impacto y se sitúa al sujeto por encima de la acción que realiza.

Al listado de términos repetitivos que acaparan la conceptualización de la discapacidad se asocian un conjunto de imágenes que operan de embajadoras del colectivo ante la opinión pública, pero que no favorecen su plena normalización. Una visión negativa, lastimosa y marginal de las personas con discapacidad que dificulta su integración en el plano mediático, primero, y en el terreno social, más tarde.

18 GARCÍA NÚÑEZ, Fernando: Cómo escribir para la prensa, Europea de Ediciones, Madrid, 1995 , p. 45. 19 IDEM, p. 45. 
La elección de un nuevo tratamiento para las informaciones relacionadas con el mundo de la discapacidad debe someterse en todo momento al paradigma del equilibrio. Resulta indispensable una adecuación terminológica a través de unos postulados lingüísticos que desconecten con un estilo periodístico hoy caduco, superado por las nuevas políticas de normalización y enquistado en modelos atrasados que proyectan ante la sociedad una imagen distorsionada del colectivo.

En este punto, resulta de vital importancia eliminar la utilización abusiva de aquellos calificativos que revelan ante la sociedad el lado menos positivo del amplio segmento que ocupa en estos momentos el mundo de la discapacidad. La repetida incidencia que hacen los medios acerca de los aspectos menos gratificantes del colectivo y la búsqueda de la individualización emocional de las noticias han cimentado un modo de hacer periodismo especialmente hostil para la discapacidad.

El adjetivo que se usa en una noticia o en una crónica debe aportar información y nunca un juicio de valor. El informador debe buscar adjetivos sobrios y sencillos ... debe huir de los adjetivos más usados (que a veces entran en el capítulo de los tópicos" 20 , señala Alex Grijelmo, quien añade, incluso, que "los adjetivos suponen una feraz fuente de controversia entre los periodistas. Para empezar, no acaban de encontrar acomodo cierto en los géneros informativos. Y, aunque se desenvuelven mejor en los opinativos, aparecen a menudo en ellos sin riqueza de expresión, formando tópicos y reiteraciones"21.

Este principio de equilibrio se sitúa entre el sensacionalismo gratuito y el imperio del eufemismo. Apostar por el rigor no significa caer en un sofisticado mecanismo de limpieza terminológica que se sitúa fuera de la realidad con la finalidad de evitar la cobertura directa de determinados asuntos especialmente delicados, que exigen sutileza a los informadores y que los colocan al amparo de un nutrido panorama de convenciones verbales para no despertar susceptibilidades.

A la falta de rigor se suma el exceso de celo. Son dos errores contrapuestos que trasladan una imagen equivocada del colectivo, bien porque priorizan los aspectos más negativos para generar adhesiones por la vía de la sensibilización efectista, bien porque huyen de su verdadera realidad para esterilizarla conceptualmente mediante vocablos que buscan lo políticamente correcto.

Ambos casos contribuyen a la aparición de estereotipos, porque se asientan en la radicalidad y en la simplificación. En un caso, se nos transfiere una imagen cargada de valores negativos; en el otro, recibimos una imagen desprovista de valores y fundamentada sólo en la superficialidad. 
Por caminos opuestos, estos dos procedimientos consiguen una fluida asimilación colectiva sin apenas reservas. Y es así porque los receptores manejan las mismas claves de interpretación que los redactores de las noticias. Han sido educados previamente en los mismos códigos y responden a los mismos criterios de aprendizaje que se han ido institucionalizando con el tiempo.

Esta instrucción se encuentra avalada por la compresión discursiva del estereotipo y por su alto grado de significatividad. Factores que favorecen la transmisión informativa y facilitan la labor periodística. Se toma como un todo, como una unidad de significación, gracias en gran medida al poder de categorización que lleva aparejado.

"La categorización es un proceso psicológico fundamental relacionado con los problemas de las percepciones y relaciones intergrupales" ${ }^{22}$, señala JacquesPhilippe Leyens, justo en su intento por establecer el valor de utilidad cognitiva del estereotipo. "En la medida que el mundo es muy complejo, se trata de aprehenderlo por medio de una severa selección de estímulos" ${ }^{23}$, asociada muchas veces a un amplio conjunto de clichés que facilitan la percepción desde medios de difusión masiva.

Lo ideal sería propinar un vuelco a esta situación para poner en valor aquellos aspectos positivos que se asocian al universo de la discapacidad. Es una apuesta difícil porque supone cambiar drásticamente los registros que se consideran actualmente en la construcción de informaciones donde los protagonistas son personas discapacitadas.

Hace falta invertir el enfoque, buscar nuevos ángulos de percepción que no ignoren las potencialidades del colectivo más allá de centrarse en sus limitaciones endémicas. Asegurar un tratamiento menos superficial, en definitiva. El objetivo es evitar la incorporación sistemática al discurso periodístico de clichés generalizadores para abordar las noticias más relevantes acaecidas en el colectivo de personas con discapacidad.

Por otro lado, esta operación de revisión sobre el tratamiento informativo que recibe la discapacidad atañe también al lenguaje, y su elección estará en función de un cambio necesario de comportamiento en los informadores a la hora de establecer las prioridades y objetivos que persiguen con sus noticias. "La selección de las palabras para expresar las ideas depende tanto de la habilidad o

22 LEYENS, Jacques-Philippe: Estereotipos, discriminación y relaciones entre grupos, Ed. McGraw-Hill, Aravaca (Madrid), 1996, p. 25.

23 IDEM: p. 117. 
destreza como de las preferencias estratégicas del escritor"24, concluye Núñez Ladevèze.

Habrá, entonces, que invertir las preferencias estratégicas de los profesionales de los medios de comunicación, para que, de esta manera, no enfaticen los rasgos más superficiales de la discapacidad y no preponderen los rasgos individualizadores sobre la extraordinaria riqueza del colectivo, basada en la diversidad y en el cambio. Como dice el propio Ladevèze, "en el funcionamiento de la lengua, lo común facilita la comunicación y lo singular la dificulta" 25 .

Es posible, incluso, establecer un listado de referencia para enumerar los estereotipos más utilizados por los medios de comunicación a la hora de abordar las informaciones relacionadas con el mundo de la discapacidad. No son categorías absolutas en sí mismos, pero reflejan un modo de aproximación a la realidad, de interpretación y de construcción de los mensajes que acarrea una inercia informativa difícil de rebatir.

Es complicado luchar contra el estereotipo, más aún si esta batalla se toma individualmente y de forma aislada. Sólo la influencia y el trabajo diario de los gabinetes de prensa del movimiento asociativo de la discapacidad tienen mínimas posibilidades de éxito para quebrar el rumbo de los acontecimientos a medio o largo plazo.

Y es así porque este tipo de construcciones mentales están incardinadas en la conciencia colectiva y su sedimentación, paulatina pero irreversible, se caracteriza por su fuerte resistencia al cambio, su dilatada perdurabilidad y su vigencia intergeneracional. El cambio de actitud informativa debe asumirse en bloque desde el entramado asociativo de la discapacidad, como se está haciendo desde hace algunos años, con objeto de cambiar la imagen del colectivo mediante informaciones más rigurosas.

Entre los estereotipos más frecuentes que concentran gran parte de la potencialidad informativa del universo de la discapacidad destacan especialmente dos:

1) La silla de ruedas. Una imagen totalitaria del colectivo.

La silla de ruedas monopoliza la visión comunicativa de la discapacidad. Es la imagen preferente del colectivo. El rasgo prioritario que preside todas las informaciones. El elemento diferencial que permite distinguir la discapacidad y establecer la pertenencia a este segmento social. 
Con el tiempo, se ha convertido en un claro estereotipo visual. El propio símbolo internacional de la discapacidad representa esquemáticamente la silueta de una silla de ruedas sobre un fondo azul. Además, la mayoría de las asociaciones de discapacitados la utilizan como elemento central de sus respectivos logotipos.

Es decir, la comunicación corporativa del movimiento asociativo ha encontrado en la silla de ruedas el motivo visual clave y el icono más representativo que traslade sin conjeturas hasta la opinión pública la identidad del colectivo a través de un poderoso vínculo de sintetismo comunicativo por medio de una imagen simple.

Aquí reside el poder y la utilidad informativa de la silla de ruedas para el extenso segmento social que comparten todas las personas con discapacidad del país. Establece una relación directa y jerarquiza la percepción del colectivo desde un único significante aceptado y comprensible.

De esta forma, los periodistas la buscan para fijar con rapidez el tema de la discapacidad en la conciencia de los receptores al primer barrido perceptivo, porque no existe ninguna otra imagen que permita situar los contenidos de las informaciones sobre el colectivo con igual eficacia.

Sin duda, es la ilustración clásica de las noticias relacionadas con personas discapacitadas. Los reporteros gráficos y los operadores de cámara necesitan captar en una instantánea o en pocos segundos de filmación sus limitaciones más evidentes con la finalidad de crear una imagen impactante y diferenciable, que no admita dudas y que refuerce los contenidos del texto periodístico.

Por eso, a este pequeño vehículo nadie le discute su condición de embajador de la discapacidad, con todas sus limitaciones e incoherencias. Está presente en la mayoría de las noticias, en la mente de los informadores y en la conciencia de los consumidores de medios de comunicación de masas. Su asociación con el mundo de la discapacidad es directa.

La apelación a la silla de ruedas como imagen del colectivo es un acto reflejo, que se realiza inconscientemente y que no es canjeable por ningún otro elemento adscrito al ámbito de la discapacidad. Es tal su capacidad comunicativa y su alto índice de representatividad que no tiene competidores directos.

El poder de significación de esta imagen no encuentra sustitutos que mantengan con éxito su mismo nivel de eficacia. Por el momento, es complicado elegir algo que le haga sombra, que transmita la identidad del colectivo con una simple ojeada a la página de un periódico o una leve mirada a los informativos de televisión.

$\mathrm{Su}$ concurso como sustento visual recurrente de las informaciones sobre discapacidad establece un proceso de identificación defectuoso con una realidad a la que no atrapa por completo. La silla de ruedas no puede ni debe abarcarlo todo. Se le han otorgado unas atribuciones excesivas que provocan desviaciones y distorsiones relevantes. 
La silla de ruedas es, de este modo, un estereotipo para categorizar el mundo de la discapacidad en una unidad simple de percepción, de fácil comprensión y asimilación inmediata. Funciona como tal, y es tan eficiente como inexacto. Como todos los clichés sociales, transmite certezas cargadas de valores connotativos.

No toda la discapacidad se ve ni reflejada ni representada en ella. El colectivo no es uniforme. La heterogeneidad y el cambio son sus dos principales variables que, en modo alguno, quedan recogidas dentro del espectro significativo de la silla de ruedas.

Sin embargo, su eficacia se fundamenta en su expansividad. Es generalizadora, jamás profundiza, pero instituye una imagen de aparente validez universal que acorta los tiempos de producción de las noticias y agiliza las formas de transmisión de las mismas, además de facilitar los modos de percepción y reconocimiento de los mensajes.

La silla se nos presenta como un estereotipo modélico porque, tal y como afirma Cano Gestoso, reproduce todas sus cualidades: es fijo, invariable, reiterativo, homogeneizador, convencional, superficial, vacío -"la falta de espontaneidad acaba desposeyendo al estereotipo de significado alguno"26- e indivisible.

En modo alguno puede cuestionarse la autoridad informativa del estereotipo, aunque sí su validez absolutamente universal y su pertinencia deontológica. Al utilizarlo, estamos incorporando una serie de valores que catalogan, casi siempre desde la distorsión y la inexactitud, la percepción colectiva del mundo de la discapacidad.

En este sentido, la silla de ruedas tiene asociados un listado de atributos que, en su conjunto, colocan en una situación de riesgo la plena integración de las personas con discapacidad: la incapacidad, la necesaria ayuda de terceros, la inmovilidad, la invalidez para desarrollar una vida normalizada, etc. Tiene predilección por las limitaciones e ignora las potencialidades. Se centra en el problema, nunca en la solución.

Cuando todo un colectivo se engloba en la percepción de una sola imagen y cuando ésta, además, se ve matizada por apreciaciones más emocionales que objetivas, entramos en el entorno del estereotipo, donde se atribuyen prejuicios ya codificados de antemano a la información sobre el mundo de la discapacidad.

Todo estereotipo tiene un área de autenticidad y un ángulo paralelo de confusión. Es cierto que la silla de ruedas debe adscribirse sin el menor margen de error al universo de las personas con movilidad reducida, pero no es menos cierto tampoco que no todos los discapacitados son físicos, que ni siquiera todos los físicos utilizan sillas de ruedas, que resulta altamente inadecuado reforzarla

26 CANO GESTOSO, José Ignacio: Los estereotipos sociales: el proceso de perpetuación a través de la memoria selectiva, Ed. Universidad Complutense, Madrid, 1993, p. 12. 
con un conjunto de matizaciones, enganchadas implícitamente desde siempre, y que representa una seria rémora para la normalización de las personas con discapacidad desde los medios de comunicación.

Deshacer esta estructura es complicado. Las formas de captar la realidad por parte de los profesionales del periodismo se sustenta en muchos casos en parámetros de percepción ya establecidos, que configuran el mundo, y lo hacen más fácil de aprehender y de ser comprendido. La principal dificultad es la inexistencia de elementos alternativos de comunicación que compensen el abandono de este tipo de estereotipos por parte de los informadores.

El movimiento asociativo necesita situarse en la vanguardia, salir al contraataque y activar los mecanismos adecuados desde sus oficinas y gabinetes de prensa. Un primer paso indispensable consiste en eludir el refugio conceptual de la silla de ruedas para retraer la consolidación de un recurso informativo que, si es supra-utilizado, acumula todas las anomalías propias de cualquier estereotipo: generalizaciones basadas en leves apuntes, adhesión a imágenes sueltas adosadas a fuertes convencionalismos y sistemas de valores, alto grado de representatividad que limita profundizar en los contenidos y consignación social de una realidad como un todo inequívoco.

\section{2) El actor por encima de la acción. La preponderancia del sujeto}

Los periodistas buscan personalizar sus informaciones, ponerles nombre y apellidos, acercarlas a una historia individual para, siguiendo un rápido procedimiento inductivo, ir de lo particular a lo general, del caso específico al conjunto de la situación.

Hasta aquí nada es original. Este mecanismo de personalización de las noticias es tan viejo como el propio periodismo. Los hechos no suceden solos, por lo que es necesario identificar a sus autores. En caso contrario, las informaciones estarían incompletas porque les faltaría el sujeto a la mayoría de sus predicados.

El pulso informativo entre el qué y el quién es una de las grandes disquisiciones que debe solucionar cada profesional del periodismo al ordenar los datos, seleccionar las fuentes, asignar los rangos de significatividad y redactar el cuerpo de sus noticias.

La absoluta paridad entre ambos es difícil. Siempre hay un extremo que se superpone y que aguanta el peso del discurso informativo. Identificar los protagonistas es tan importante como precisar sus acciones. El periodismo de declaraciones se basa con descaro en la autoridad del sujeto mientras que las noticias sobre accidentes de tráfico o desastres naturales, por ejemplo, se centran principalmente en los acontecimientos.

Los periodistas evitan caer por completo en alguna de estos dos modos de concebir su trabajo. Por eso, las ruedas de prensa, ejemplo máximo del periodismo basado en afirmaciones personales, realizadas para colmo en un espacio donde se 
ha convocado a los medios de manera interesada, se reconstruyen en el papel impreso en forma de acontecimientos, para bordear la versión oficial y pasarla por el tamiz del formato periodístico.

Para Grijelmo, "la liberalización de la información radiofónica puso de moda en España el periodismo de declaraciones. Durante el franquismo, todas las emisoras de radio estaban obligadas a conectar con la emisora estatal, Radio Nacional de España -controlada por el Gobierno, para que nadie pudiera ofrecer una versión diferente de los hechos que no fuera la oficial" ${ }^{27}$.

Sin embargo, el mundo de la discapacidad constituye una excepción interesante. La personalización de las informaciones es aquí un recurso generalizado, pero tiene un claro efecto boomerang porque consigue el efecto contrario al pretendido.

El interés por concretar la identidad del sujeto de la acción se utiliza para potenciar socialmente los rasgos y las características que se atribuyen al colectivo, convirtiendo la personalización en un estereotipo. Si bien trata de implicar al protagonista de la noticia como el constituyente más relevante de la información, se acaba proyectando una imagen general del colectivo donde éste se convierte en un modelo representativo para el resto de las personas con discapacidad de cara a la sociedad.

La preponderancia del sujeto es el argumento básico de muchas informaciones sobre casos individuales que escapan a los selectivos mecanismos de los gabinetes de prensa del movimiento asociativo de la discapacidad y que, por otra parte, representan el grueso más importante de las informaciones que los medios de comunicación ofrecen sobre ésta.

Principalmente, esta situación se reproduce porque, en muchas ocasiones, "el periodista debe motivar la noticia, debe lograr que los lectores se sientan concernidos por ella. Para lograrlo, atenderá a los factores humanos, pues son ellos los que, con independencia de las diferencias sociales, generacionales, espaciales, temporales o culturales, permiten que el lector vea a los protagonistas de la noticia como unas personas próximas a sus propias procupaciones" 28 .

De esta forma, es más fácil generar un clima de concienciación en los receptores entorno a las informaciones. La personalización extrema de las noticias persigue que los destinatarios de las mismas sientan la inevitable inclinación de situarse en el lugar de sus afligidos actores, elevando considerablemente el listón emocional y colocándose sin reservas en un punto más cercano al sensacionalismo y más lejano del rigor periodístico en sentido estricto. Por eso, "los estereotipos son mayoritariamente concebidos y medidos como una lista de

27 GRIJELMO, Alex: El estilo del periodista, Ed. Taurus, Madrid, 1997, p. 44.

28 LÓPEZ GARCÍA, Antonio: Escritura e información. Ed. Cátedra, Madrid, 1996, p. 15. 
rasgos personales que se aplican a los miembros de un grupo, casi siempre rasgos de personalidad"29.

Además, las oficinas de prensa de las asociaciones de discapacitados gestionan una parte mínima de las informaciones que genera el colectivo. Éste es el máximo problema que encuentran tanto sus dirigentes como los profesionales de la comunicación que trabajan en estos departamentos a la hora de combatir con esperanzas de éxito la persistencia del estereotipo.

Reconducir esta tendencia no es fácil. El verdadero potencial informativo de la discapacidad se encuentra atomizado, diseminado en casos particulares que se toman como puntuales y se difunden luego con un evidente barniz generalizador.

Volvamos sobre el terreno para advertir y comprobar el fenómeno en la prensa de manera regular. El País, en su edición del 30 de junio de 2001, publicaba en la página 10 del cuadernillo de Andalucía las dos noticias siguientes: "Un vecino de Almería con problemas de movilidad muere en un incendio" y "Absuelto un enfermo mental que apuñaló 66 veces a su madre". Unos días después, el 3 de julio, $A B C$ y el propio El País repiten la misma información con un titular parecido en sus respectivas secciones de Andalucía: "Hallado un deficiente muerto por asfixia en el maletero de un coche" y "Hallado muerto un disminuido psíquico que desapareció en El Puerto", mientras, nuevamente $A B C$, en su número correspondiente al día 12 del mismo mes, titula en la sección de Sevilla; "Un anciano discapacitado, en estado grave tras incendiarse su vivienda".

No es necesario insistir a estas alturas sobre la estructura clásica de la información periodística ni incidir en los condicionantes que se derivan de la sujeción al modelo de la pirámide invertida. Estas pautas de redacción jerarquizan los contenidos de las informaciones, empezando por lo más importante y terminando, ya en el desarrollo textual de las noticias, por los aspectos más secundarios.

La utilización de este tipo de titulares con tanta frecuencia genera un efecto distorsionador. Facilitan las generalizaciones y colocan en la cúspide de lo noticiable, en el vértice superior de la pirámide, el matiz de la discapacidad, que se convierte así en el principal motor de la información, en su atractivo prioritario, en el dato más destacado, el que proporciona relevancia y distinción a las informaciones.

Los titulares de noticias relacionadas con la discapacidad se encuentran cargados de expresiones como "un deficiente muerto", "un anciano discapacitado" o "hallado muerto un disminuido". Es aquí donde, desde un punto de vista lingüístico, se concentra el verdadero peso informativo de las noticias. Se instituye, de esta forma, un paradigma periodístico relacionado con el colectivo mediante

29 CANO GESTOSO, José Ignacio: Los estereotipos sociales: El proceso de perpetuación a través de la memoria selectiva, Ed,. Universidad Complutense, Madrid, 1993, p. 132. 
el cual, un acontecimiento ordinario, se eleva a la categoría de extraordinario al entrar en juego como factor determinante la condición de discapacitados de sus protagonistas.

Las limitaciones, rémoras y valores que se adjudican al término discapacidad multiplican su potencial informativo, circunstancia que es apreciada y recogida desde los titulares, que apelan, por su propia naturaleza, a un proceso de condensación donde sólo tiene cabida lo exclusivamente relevante.

La discapacidad es noticia en sí misma y convierte en noticia hechos indiferentes. Discapacitado, minusválido, inválido, enfermo, deficiente, disminuido o retrasado conforman una dilatada nómina de adjetivos que pueblan los titulares y se dispersan en el desarrollo de las informaciones. Tienen una labor descriptiva que, centrada en precisiones reforzadoras de la identidad del individuo, apenas desbrozan con argumentos las causas y las dimensiones de los problemas del colectivo.

Estos atributos, siempre personalizados, adquieren el máximo protagonismo dentro de las noticias. Le imprimen, por lo tanto, la personalidad y la significación necesarias para reunir los requisitos mínimos que se exigen desde los medios para convertir un hecho en noticiable: novedad, diferenciación, extrañeza, notoriedad, etc.

Esta concatenación de elementos impone un viaje discursivo ajustado a los parámetros de la inducción. Se va de lo particular a lo general. Las personas, hasta ese momento anónimas, aparecen ante la opinión pública como paradigmas del colectivo. Las informaciones los convierten en representantes aislados que son asimilados en virtud de un conjunto de valores paralelos que vienen marcados y definidos desde la propia adjetivación de los titulares.

El procedimiento es repetitivo. Las herramientas de control informativo puestas en marcha por las asociaciones de discapacitados son todavía demasiado limitadas para contrarrestar el flujo de noticias inconexas que genera el colectivo a partir de casos individuales y que plantean serios problemas porque sus repercusiones son claramente negativas, tanto en los medios como en la sociedad.

Nos encontramos ante una sucesión imparable de noticias que, apostando por la individualización, provocan el fenómeno de la generalización sistemática de sus contenidos. Éste es el segundo gran estereotipo que gravita poderoso sobre el mundo de la discapacidad. Se produce, especialmente, cuando un hecho cotidiano es asumible sin reservas como noticia si su autor es una persona discapacitada, con el agravante añadido de irradiar sus efectos sobre la totalidad del colectivo.

La colocación del actor siempre por encima de la acción deshace con brusquedad el equilibrio informativo exigible a cualquier noticia. La preponderancia del sujeto y, sobre todo, la condición de discapacitado de éste despierta un interés especial entre los periodistas que es complicado deshacer. 
Gran parte de estas noticias serían prescindibles, podrían desconsiderarse, no aportan nada nuevo, pero establecen un juego de sintonías, de acuerdos y de aceptaciones entre informadores e informados que las hacen influyentes en el enmarañado tejido de la actualidad, por eso se cuelan en él con tanta facilidad.

\section{Más cantidad de información, sobre todo institucional}

Durante los últimos años se ha incrementado el flujo informativo relacionado con el mundo de la discapacidad. La existencia de una legislación específica, la presión creciente del movimiento asociativo para su cumplimiento y la proliferación de un sistema público de políticas sociales ha, sensibilizado primero, y obligado, después, a las instituciones públicas de nuestro país.

Las distintas administraciones españolas han colocado los programas, actividades y subvenciones destinados al colectivo de discapacitados entre las prioridades de sus departamentos de asuntos sociales o bienestar social. Esta circunstancia ha colocado el tema de la discapacidad en las agendas de los medios de comunicación, en las convocatorias de los gabinetes de prensa institucionales y en la regular difusión informativa que se realiza a diario desde ellos.

Esta toma de conciencia, verdadera asignatura pendiente de la Administración española a lo largo de los años, ha supuesto la adopción de políticas específicas para las personas con discapacidad, ha legitimado la ampliación de sus organigramas institucionales mediante la incorporación de áreas responsabilizadas en exclusiva de las cuestiones sociales -donde se insertan las respuestas oficiales a las demandas del colectivo (Ministerio de Trabajo y Asuntos Sociales, Consejería de Asuntos Sociales, Áreas de Bienestar Social de las distintas diputaciones, delegaciones municipales de bienestar social, etc)-, ha fundamentado, en definitiva, el desarrollo de iniciativas y proyectos que, como noticias de interés social, han tenido acomodo informativo creciente en los medios de comunicación.

Por lo tanto, el global de las actuaciones públicas que giran en torno al colectivo de las discapacidad se convierte regularmente en noticias para los profesionales de los medios. Nuestras instituciones componen un mapa de atracción informativa en todos aquellos núcleos de población donde se asientan. Las decisiones de sus órganos de gobierno son una fuente diaria de material noticiable para los informadores.

Ayuntamientos, diputaciones, consejerías, parlamentos y ministerios diseñan un itinerario para la información de los asuntos públicos que, a través de comparecencias y ruedas de prensa, transfieren cotidianamente sus actuaciones más relevantes a los medios de comunicación. Conforme la discapacidad ha ido colándose en sus agendas, las informaciones del colectivo han sido más asiduas.

Las instituciones han representado un formidable tirón informativo para el colectivo de la discapacidad. La elaboración de planes de acción, junto a la 
aprobación de normativas específicas, como la Ley de Atención de las Personas con Discapacidad en Andalucía, ha generado un acercamiento indirecto de los medios al universo de la discapacidad mediante la interlocución siempre acreditada de nuestras instituciones públicas.

Ha contribuido de manera decisiva a este incremento de apariciones en medios de comunicación la fluida relación institucional que se ha consolidado entre las administraciones y las entidades de personas con discapacidad. La firma de convenios y la puesta en marcha de líneas de actuación conjuntas han desencadenado una dilatada nómina de informaciones sobre el colectivo.

Las asociaciones representativas del heterogéneo mundo de la discapacidad caminan desde hace tiempo junto a las instituciones, de las que reciben subvenciones, ayudas y apoyos para el mantenimiento de sus actividades y servicios. Este bagaje en común se traducen en presentaciones de proyectos, inauguración de instalaciones o convocatorias de prensa donde los medios de comunicación son invitados a difundir los contenidos de sus iniciativas.

Las instituciones, por lo tanto, han servido de reclamo ante los medios hacia el colectivo de la discapacidad para que éstos, a través de su testimonio y respaldo, orienten el curso de sus informaciones acerca de las acciones más destacadas y los problemas estructurales que inciden sobre los discapacitados.

La apelación a las instituciones como polo de atracción informativo ha sido una constante durante los últimos años. Se establece de esta manera una interesante simbiosis donde las administraciones cumplen ante la opinión pública el compromiso social que les demanda la sociedad en la atención obligatoria a colectivos desfavorecidos y con problemas de integración, mientras el colectivo recibe una fluida vía de ayudas que les permite, por otra parte, acaparar el interés de los medios de comunicación.

Esta sucesión de acontecimientos ha reportado a las asociaciones de discapacitados dos consecuencias concatenadas entre sí; la dotación de recursos extraídos de los fondos públicos y una mayor presencia como referentes informativos en los medios de comunicación ante la posibilidad de desarrollar actividades cada vez más numerosas y significativas. De esta forma, el colectivo ha conseguido ser, primero, más fuerte y, segundo, más conocido.

La relación establecida con cualquiera de los diferentes niveles de la administración del Estado, comenzando por el Congreso y terminando en los distritos municipales de barriadas, no ha cercenado en modo alguno la autonomía operativa de las asociaciones de discapacitados, que han ensanchado sus infraestructuras y ampliado el número de servicios en la mayoría de los casos.

El universo de la discapacidad es capaz por sí mismo de convertirse en noticia sin la necesidad de valores añadidos. Sin embargo, la estrategia de refuerzos emprendida con nuestras instituciones ha mejorado la relación con su entorno, ha atornillado definitivamente sus estructuras como movimiento asociativo y ha 
multiplicado sus posibilidades de colarse en el abigarrado panorama de la actualidad informativa.

\section{Más calidad en la información. Creación de gabinetes de comunicación y oficinas de prensa}

La presencia en sociedad de cualquier institución, sea pública o privada, se mide por el número de apariciones acumuladas en los medios de comunicación. Esta aseveración, que no es categórica al cien por cien, si establece un paradigma inequívoco en la proyección externa de instituciones y entidades: su percepción social, el grado de confianza que generan, el conjunto de expectativas e incertidumbres que tienen asociadas, la definición de su imagen y las adhesiones o reprobaciones que consiguen están especialmente ligadas al grueso de informaciones que aparecen, sobre sus actividades y actuaciones, en los medios de comunicación.

La necesidad de ejercer presión ante las instituciones, de legitimar la realización de sus proyectos, de consolidar su presencia en su entorno, de incrementar el índice de competitividad, de mejorar la imagen pública y de generar un conocimiento adecuado en el seno de la sociedad ha impulsado a toda clase de entidades a sustentar su comunicación mediante gabinetes específicos en manos de profesionales especializados.

Esta percepción de utilidad ha calado durante la última década en las entidades de carácter social y sin ánimo de lucro de nuestro país. Fortalecer la presencia y hacerse notar obliga a activar estrategias de comunicación tanto externas como internas.

Para ello, ha sido imprescindible una solidez previa de las asociaciones de discapacitados que, tras encontrar respuestas a sus necesidades primarias para su subsistencia una vez constituidas, han percibido con claridad la conveniencia de incluir en sus estructuras, cada vez más complejas y en constante crecimiento, gabinetes de comunicación y oficinas de prensa que penetran por vez primera en el universo de las entidades sociales como una importación inevitable del mundo empresarial, donde la comunicación de la imagen corporativa se ha situado desde hace décadas en el basamento de sus planes estratégicos y de sus políticas de expansión comercial.

Así, el movimiento asociativo en el ámbito de la discapacidad ha reconocido la importancia de la comunicación como vehículo para colocar en el interior de la opinión pública sus problemas y exigencias y, a la vez, conectar mecanismos de presión ante los responsables encargados de activar políticas de normalización socio-laboral para discapacitados.

Gabinetes de comunicación se han venido constituyendo en los últimos años dentro del organigrama de las asociaciones de discapacitados más influyentes, representativas y consolidadas del país. La puesta en marcha de oficinas de prensa 
y la edición de revistas especializadas con criterios de diseño y redacción profesionalizados ha tendido puentes hacia los medios de comunicación, la sociedad en general y el interior de los propios colectivos sobre los que proyectan sus actividades:

Durante los últimos años se han multiplicado, tanto en las empresas como en las instituciones, las intervenciones sistemáticas sobre la imagen corporativa, creándose en muchos cargos departamentos encargados de su gestión. Con ello han empezado también a superarse los prejuicios y cerrazones que inicialmente limitaban el alcance y el contenido de la comunicación a acciones superficiales, particulares y aisladas ${ }^{30}$.

La profesionalización de la comunicación en el terreno social ha ganado para el colectivo un hueco entre los contenidos que componen ese complejo panorama diario de la información de actualidad. Se ha incrementado exponencialmente el número de apariciones en prensa, radio y televisión. El colectivo se ha transformado en una fuente solvente y recurrente para los informadores, presentándose ante la sociedad y exhibiendo, por encima del prejuicio, sus verdaderas señas de identidad. "La comunicación positiva y coherente de todas y cada una de esas señas de identidad contribuye a generar una imagen corporativa, que es lo que se instala progresivamente en la opinión del público"31.

La creación de gabinetes de comunicación propicia una dinámica de interrelaciones mutuas con los medios y éstos, a su vez, disponen de unos resortes de información acreditados en el seno de un colectivo que, por naturaleza, es complejo, atomizado e invertebrado.

La incorporación del periodista de gabinetes y oficinas de prensa especialista en comunicación social a la agenda ordinaria de los profesionales de la comunicación diaria ha mejorado significativamente la relación entre los medios y el colectivo. Se ha generado de esta forma un clima de confianza, de reconocimiento profesional recíproco y de influencias en ambos sentidos cuyo logro principal ha estado representado por un acercamiento estable y duradero del movimiento asociativo de la discapacidad en la rutina de trabajo de los medios de comunicación.

La utilización de un mismo lenguaje, el sometimiento a las técnicas de redacción periodísticas, el dominio de las formas y los tiempos comunes en los distintos medios y la asimilación del principio de legitimidad profesional que 
subyace al funcionamiento de estos gabinetes reflejan un cuadro de sintonías con los profesionales de los medios que facilita la pertinencia informativa de estos instrumentos, adosados al aparato organizativo de las asociaciones de discapacitados.

La oficina de prensa, por su parte, convierte en información la actualidad de cada movimiento asociativo. Esta vinculación entre el mundo de la discapacidad y de los medios posibilita una relación sostenida que eleva el techo informativo de las ONGs, estableciéndose una transferencia directa de datos y un intercambio permanente entre el colectivo y los medios.

La discapacidad ha encontrado en los gabinetes de comunicación y oficinas de prensa unas herramientas formidables para hacerse notar en la sociedad y librarse un hueco en el complicado ruedo de la información de actualidad. "Estas relaciones -con los medios- son de doble sentido" ${ }^{32}$, desde las asociaciones hacia la prensa y a la inversa, de la prensa hacia las asociaciones.

Gracias a esta nueva tesitura, el movimiento asociativo se convierte en un difusor controlado y controlable de informaciones. Controlado porque al recaer estas funciones en profesionales de la comunicación someten su trabajo a los criterios establecidos dentro de la labor periodística, controlable; porque los profesionales de los medios disponen de unos referentes sólidos para comprobar, matizar y contrastar las informaciones recibidas.

De esta forma, el mundo de la discapacidad en España ha visto como su presencia en los medios se ha ido ensanchando desde un punto de vista cuantitativo y cualitativo. Cuantitativo porque se han multiplicado el número de apariciones en medios de comunicación, cualitativo; porque se ha conseguido en paralelo un tratamiento de las informaciones más preciso, riguroso y exhaustivo que, aunque no afecte al total de las apariciones, si constituye un poderoso punto de partida a la hora de invertir las formas y los modos tradicionales en la redacción de noticias relacionadas con el mundo de la discapacidad.

El respaldo de una legislación específica y el compromiso asumido por instituciones públicas y privadas han comportado una serie de sinergias en cadena cuyos resultados más significativos han despertado el interés de los medios, bien por la relevancia del tema, bien por la eficacia en el trabajo de los gabinetes de comunicación del propio colectivo.

El gran reto en estos momentos es liberar a la información sobre la discapacidad de una serie de rémoras conceptuales que perpetúan todavía una imagen inexacta del colectivo. La utilización abusiva de estereotipos, la superficialidad en el tratamiento y la banalización de los contenidos a través de elementos sensibi-

32 PIÑUEL RAIGADA, José Luis: Teoría de la comunicación y gestión de las organizaciones, Ed. Síntesis, Madrid, 1997, p. 223 
lizadores en el discurso han trasladado hasta la sociedad una percepción confusa y equívoca de las personas con discapacidad.

Este efecto de falta de focalización ha sido mejorado por la acción de los gabinetes de comunicación y oficinas de prensa que funcionan con normalidad desde hace unos años en el colectivo de la discapacidad. Desde los gabinetes se diseñan, preparan y ejecutan las estrategias de comunicación externa e interna de cualquier organización, sean políticas (partidos), económicas (empresas) o sociales, como es el caso de las entidades formadas por discapacitados.

$\mathrm{Y}$ es así porque "vivimos en una sociedad de organizaciones. Los seres humanos nos unimos en grupos afines para defender nuestras ideas, llevar a cabo proyectos, crear, producir, ... y en las que necesitamos de los otros para desarrollarnos" "33. Es decir, la vertebración de la sociedad se compone de una infinidad de cédulas independientes entre sí pero que, en su actividad rutinaria, necesitan establecer constantes intercambios con su entorno, por lo que les es fundamental la obligación de comunicarse oportuna y correctamente.

Sin embargo, aún queda mucha información de circulación libre, que afecta a casos particulares y situaciones personales extremas, que, destiladas informativamente por medio de estereotipos y clichés generalizadores, enfatizan una imagen del colectivo escorada hacia el lado de la grima, alejada del concepto de justicia social más incardinado en los cimientos de cualquier sistema democrático, como el nuestro.

Los gabinetes de comunicación han destapado las potencialidades de comunicación de un colectivo que, por sus peculiaridades y el alto grado de sensibilización social que despierta, es susceptible de ser convertido en noticia con facilidad. Este es un handicap que juega a favor de sus posibilidades de éxito.

Por otra parte, la discapacidad, como otros muchos temas relevantes, facilitan la huida de la estricta información política en los medios, auténtico buque insignia de la actualidad. Aunque la administración ha aupado al movimiento asociativo gracias a una fluida vía de ayudas y subvenciones, los medios premian con una dedicación reposada aquellas noticias que escapan del círculo cerrado de instituciones, partidos, colegios profesionales y sindicatos.

Las noticias de interés social sintonizan con una preocupación creciente de la opinión pública por cuestiones solidarias. La discapacidad ocupa hoy un espacio informativo en un segundo nivel tras las noticias de carácter político, económico, cultural y deportivo. Ascender al primer puesto del ranking parece imposible, pero es tarea indiscutible para los gabinetes de comunicación conseguir que su posición relativa en el vasto contexto de la actualidad sea cada vez más conocida, acomodada y relevante.

33 ONGALlo, Carlos: Manual de comunicación, Ed. Dykinson, Madrid, 2000, p. 3. 
No obstante, una mayor profusión de apariciones tampoco garantiza en estos momentos una mejora proporcional de la imagen global del colectivo. La redefinición que el concepto discapacidad ha experimentado en los últimos años es hoy una referencia obligada para construir informaciones rigurosas. Centrar el valor de la noticia en las capacidades en lugar de destacar las limitaciones supone el punto de partida para, con el trabajo ordenado y sistemático de los gabinetes de comunicación y oficinas de prensa, conseguir un bruto de informaciones sobre la discapacidad más acordes con los nuevos tiempos.

Para ello, estos profesionales desempeñan un papel prioritario en la educación terminológica de sus compañeros de profesión. En la actualidad, los gabinetes de comunicación, además de informar, están formando a periodistas de los medios en nuevas categorías y conceptos. La normalización de las personas con discapacidad en la sociedad de la información es una meta complicada si no se consigue paralelamente en sus medios de comunicación de masas.

Luchar contra el estereotipo es difícil, más en una sociedad que ha desdeñado el discurso de la razón para adoptar el de la imagen. El hombre ha pasado de ser un homo sapiens y se ha convertido en un homo videns. El imperio de los medios audiovisuales ha dominado desde el final de la II Guerra Mundial hasta nuestros días la manera de acceder al conocimiento y de capturar la realidad de las cosas.

El colectivo de la discapacidad no ha podido desprenderse de esta estructura cognitiva. La sociedad ha interiorizado a través de un reducido listado de clichés una imagen equívoca de un sector de la población diverso, escasamente vertebrado y con una limitación sistemática para acceder con normalidad a los medios de comunicación.

Este conjunto de factores ha ejercido con el tiempo una negativa influencia en los esquemas de percepción de los destinatarios de los medios. La labor de los periodistas especializados que trabajan en las oficinas de prensa y gabinetes de comunicación del propio colectivo ha propiciado un mejor tratamiento en los contenidos, así como la aparición de unos mensajes más selectivos sobre el universo de la discapacidad. Sin olvidar, el establecimiento de unas relaciones más fluidas y de un intercambio permanente de información con los profesionales de los medios.

Estos departamentos se han convertido en fuentes habituales de información para los medios, que las reconocen, las tienen en cuentan y las estiman. Los gabinetes son los encargados, pues, de proyectar hasta la sociedad la postura oficial del colectivo. Se han convertido en la voz autorizada y en el instrumento de referencia a la hora de abordar informaciones relacionadas con el mundo de la discapacidad.

El trabajo diario de los gabinetes de prensa ha posibilitado un incremento en la calidad expositiva de los mensajes, un mayor conocimiento de las claves del 
colectivo y una huida de tratamientos efectistas. La primera consecuencia de este orden de cosas es que se ha profesionalizado la información. Existen técnicos en comunicación, formados en las distintas facultades de Ciencias de la Información de España, que son parte cotidiana de las plantillas de las grandes asociaciones de discapacitados del país, junto a trabajadores sociales, fisioterapeutas, psicólogos o expertos en lengua de signos.

Su presencia ha sido fundamental para conseguir una mayor presencia del colectivo entre los contenidos de la actualidad periodística y para que el tratamiento de los mensajes sea más cercano a la realidad, más certero en los datos y más descargado de recursos fáciles que, desde un punto de vista lingüístico, compensan la falta de documentación en la elaboración de las noticias. La documentación ordenada y sistemática es una palanca excepcional para romper las perversiones del prejuicio y para vencer los efectos generalizadores del estereotipo.

En este sentido, los profesionales de los medios y de estos gabinetes de comunicación corporativa del mundo de la discapacidad se precisan mutuamente. Establecen una sinergia de ventajas recíprocas. Los primeros porque hacen de interlocutores entre la sociedad y el colectivo, los segundos porque funcionan como intermediarios entre los medios y el mundo de la discapacidad.

Por otro lado, los gabinetes de prensa propios del movimiento asociativo se han revelado como unos excelentes puntos de contrastación de informaciones para los medios de comunicación, que recurren a ellos a la hora de determinar la veracidad y la exactitud de las noticias.

Este tipo de oficinas concentran la difusión de informaciones desde el colectivo. Es decir, ejercen un control sobre el proceso de emisión que evita duplicidades, contradicciones o confusiones derivadas del escaso conocimiento de la situación. Su dominio del terreno garantiza una información de calidad desde el origen y genera una mayor peso relativo de los mensajes de la discapacidad en el enrevesado y competido espacio de la actualidad periodística.

Así, estos gabinetes han ocupado el lugar y han acaparado las funciones que, hasta hace poco, realizaban con discutible éxito personas ajenas a la profesión periodística, en la mayoría de los casos vinculadas a los órganos de dirección del movimiento asociativo.

La necesidad de contar con técnicos especializados y el crecimiento expansivo de las asociaciones de discapacitados más representativas han favorecido su creación y puesta en marcha. Con el tiempo, han dejado de ser una figura novedosa y extraña para convertirse en una parte esencial de la capacidad operativa y de la estructura orgánica de las ONGs de discapacitados españolas más influyentes.

En definitiva, con el tiempo se han corregido parcialmente algunos errores mayúsculos que se han venido repitiendo sistemáticamente en la elaboración de noticias sobre la discapacidad desde los medios de comunicación. 
El extraordinario potencial informativo del colectivo y la incapacidad de los gabinetes de comunicación y oficinas de prensa del movimiento asociativo a la hora de controlar y supervisar con acierto el flujo de información que los medios reciben de la discapacidad son dos graves problemas estructurales en el proceso actual de producción, elaboración y difusión de noticias donde este colectivo se presenta ante la sociedad como protagonista.

Por último, la consolidación en la sociedad de las ONGs compuestas por personas discapacitadas, el apoyo institucional creciente, la apelación a profesionales de la comunicación para mejorar las relaciones con los medios y la asunción de una nueva terminología, más correcta a la vez que menos sensacionalista, son motivos suficientes como para ser optimista desde la certeza de que la situación actual ha mejorado, pero con la convicción de que es manifiestamente mejorable.

\section{Bibliografía:}

- ARMENDIA, José Ignacio: La información, Euskal Herriko Unibertsitateko Argitalpen, Bilbao, 1998.

- BENITO, Ángel: La invención de la actualidad: técnicas usos y abusos de la información, Fondo de Cultura Económica, Madrid, 1995.

- CANO GESTOSO, José Ignacio: Los estereotipos sociales: el proceso de perpetuación a través de la memoria selectiva, Ed. Universidad Complutense, Madrid, 1993.

- GARCÍA NÚÑEZ, Fernando: Cómo escribir para la prensa, Europea de Ediciones, Madrid, 1985.

- GINER, Salvador: Sociología, Ed. Nexos, Barcelona, 1990.

- GRIJELMO, Alex: El estilo del periodista, Ed. Taurus, Madrid, 1997.

- GUTIÉRREZ PALACIO, Juan: Periodismo de opinión, Ed. Paraninfo, Madrid, 1984.

- HANS, Johnson: La gestión de la comunicación, Ediciones Ciencias Sociales, Madrid, 1991.

- HERNANDO, Bernardino M: Lenguaje de la prensa, Ed. Edudema, Madrid, 1990.

- LEYENS, Jacques-Philippe: Estereotipos, discriminación y relaciones entre grupos, McGraw-Hill, Aravaca (Madrid), 1996.

- LÓPEZ GARCÍA, Antonio: Escritura e información, Ed. Cátedra, Madrid, 1996.

- MASCARAY, José y Joan Elías: Más allá de la comunicación interna, Gestión 2000, Barcelona, 1998.

- NIETO, Alfonso e IGLESIAS, Francisco: Empresa informativa, Ed. Ariel, Barcelona, 1993. 
- NÚÑEZ LADEVÈZE, Luis: Métodos de redacción periodística y fundamentos de estilo, Ed. Síntesis, Madrid, 1993.

- ONGALlO, Carlos: Manual de comunicación, Ed. Dykinson, Madrid, 2000.

- PINILLOS SUÁREZ, Pedro J: La empresa informativa, Ediciones Castillo, Madrid, 1975.

- PIÑUEL RAIGADA, José L: Teoría de la comunicación y gestión de las organizaciones, Ed. Síntesis, Madrid, 1997.

- REIG, Ramón: Medios de comunicación y poder en España: prensa, radio, televisión y mundo editorial, Ed. Paidós, Barcelona, 1998.

- URABAYEN, Miguel: Estructura de la información periodística, Ed. Mitre, Barcelona, 1988.

- VARIOS, La empresa ante los medios de comunicación, Ed, Deusto, Bilbao, 1992.

- VARIOS, Medios de comunicación social, Fundación Germán Sánchez Ruipérez, Madrid, 1992. 